\title{
Chicken IgL Gene Rearrangement Involves Deletion of a Circular Episome and Addition of Single Nonrandom Nucleotides to Both Coding Segments
}

\author{
Wayne T. McCormack, Larry W. Tjoelker, $\dagger$ \\ Louise M. Carlson," Bronislawa Petryniak," \\ Carolyn F. Barth, $\ddagger$ Eric H. Humphries, $\ddagger$ \\ and Craig B. Thompson ${ }^{\star} \dagger$ \\ * Howard Hughes Medical Institute \\ University of Michigan Medical School \\ Ann Arbor, Michigan 48109 \\ tDepartment of Microbiology and Immunology \\ University of Michigan Medical School \\ Ann Arbor, Michigan 48109 \\ $\ddagger$ Department of Microbiology \\ University of Texas Southwestern Medical Center \\ Dallas, Texas 75235
}

\section{Summary}

Chicken immunoglobulin light chain $\left(\lg _{L}\right)$ gene rearrangement has been characterized. Rearrangement of the single variable $\left(V_{L}\right)$ segment with the single joining $\left(J_{L}\right)$ segment within the chicken $\lg _{L}$ locus results in the deletion of the DNA between $V_{L}$ and $J_{L}$ from the genome. This deletion is accomplished by a molecular mechanism in which a precise joining of the $\mathbf{l g}_{L}$ recombination signal sequences leads to the formation of a circular episomal element. The circular episome is an unstable genetic element that fails to be propagated during B cell development. Evidence was obtained that the formation of the circular eplsome is accompanied by the addition of a single nonrandom base to both the $V_{L}$ and $J_{L}$ coding segments. The subsequent joining of the $V_{L}$ and $J_{L}$ segments appears to occur at random, as we observed at least 25 unique $V-J$ junction sequences, 11 of which are out-of-frame. A novel recombination mechanism that accounts for the observed features of chicken $\lg _{L}$ gene rearrangement is discussed.

\section{Introduction}

The chicken immunoglobulin light chain $\left(\mathrm{lg}_{\mathrm{L}}\right)$ locus consists of single functional $V_{L}$ (variable), $J_{L}$ (joining), and $C_{L}$ (constant) gene segments that are aligned along 5.4 kilobases (kb) of DNA in the germ line, and an upstream family of $25 V_{L}$ pseudogenes (Reynaud et al., 1985, 1987). A functional $\lg _{L}$ gene is created during $B$ cell development by in-frame joining of the $V_{L}$ and $J_{L}$ coding sequences. Diversity of the chicken $\lg _{L}$ gene is generated by gene conversion of the rearranged $V_{L}$ segment with pseudogene donor sequences during $B$ cell development in the bursa of Fabricius (Reynaud et al., 1987; Thompson and Neiman, 1987).

The chicken $\lg _{\mathrm{L}}$ locus, because of its small size and unique germ-line structure, provides a novel in vivo model for the study of the $\mathrm{V}-\mathrm{J}$ joining process. While the molecular mechanism of $\mathrm{V}-\mathrm{J}$ joining in chicken $B$ cells has not been characterized, the chicken $\lg _{\mathrm{L}}$ gene segments possess recombination signal sequences similar to those that flank the $\mathrm{Ig}$ and $\mathrm{T}$ cell receptor (TCR) gene segments in other vertebrate species (Tonegawa, 1983; Hood et al., 1985; Yancopoulos et al., 1986). The germ-line $V_{L}$ gene segment is followed by a heptamer and nonamer sequence separated by a 23 bp spacer region, whereas the germ-line $J_{L}$ segment is preceded by a heptamer and nonamer sequence separated by a 12 bp spacer (Reynaud et al., 1985). In mammals, these signal sequences appear to target lymphoid-specific recombination events (Akira et al., 1987). Mammalian Ig gene rearrangement has been hypothesized to occur by unequal sister chromatid exchange, intramolecular DNA deletion, deletion and reintegration, and/or chromosomal inversion (reviewed by Kronenberg et al., 1986).

Analysis of $\mathbf{4 8}$ clonal chicken $B$ cell lines demonstrated that the DNA between $V_{L}$ and $J_{L}$ is lost from the genome during $\lg _{L}$ gene rearrangement. After determining the complete nucleotide sequence of the germ-line $V_{L}$ and $J_{L}$ gene segments and the region between them, oligonucleotide primers were designed to rescue potential intermediates in the deletional process using the polymerase chain reaction (PCR; Saiki et al., 1988). Evidence was obtained that the DNA between $V_{L}$ and $J_{L}$ is precisely excised and circularized during rearrangment. The resultant circular episome fails to be propagated during B cell development, and is therefore absent in most, if not all, mature B cells. Rearranged $\lg _{\mathrm{L}}$ genes were isolated from an embryonic bursal cDNA library and cloned following PCR amplification from embryonic lymphoid tissue DNA using $\lg _{\mathrm{L}}$ specific primers. Analysis of 85 cloned $V-J$ coding joints revealed considerable $\mathrm{V}-\mathrm{J}$ junctional diversity, with at least 25 distinct $V-J$ joints identified. Surprisingly, comparison of the $\mathrm{V}-\mathrm{J}$ coding joint sequences with the germline sequences suggests that single nonrandom nucleotides are added to the $V_{L}$ and $J_{L}$ coding ends during the deletional process and prior to $\mathrm{V}-\mathrm{J}$ joining.

\section{Results}

Chicken $\lg _{L}$ Gene Rearrangement Results in Loss of the DNA between $V_{L}$ and $J_{L}$

The genomic organization of the $\lg _{\mathrm{L}}$ locus of the SC chicken and the DNA probes used in these experiments are shown in Figure 1A. Rearrangement of the chicken $\lg _{L}$ gene results in the joining of the $V_{L}$ and $J_{L}$ coding segments. The fate of the $1.8 \mathrm{~kb}$ of DNA between $V_{L}$ and $J_{L}$ has not previously been determined. To address this issue, 48 clonal chicken $B$ cell lines and tumors were examined for the presence of the DNA segment between $V_{L}$ and $J_{L}$. In all instances probes derived from the region between $V_{L}$ and $J_{L}$ detected only germ-line segments retained in unrearranged alleles (data not shown). Thus, the DNA between $V_{L}$ and $J_{L}$ is deleted from the genome during $V-J$ joining. 
A.
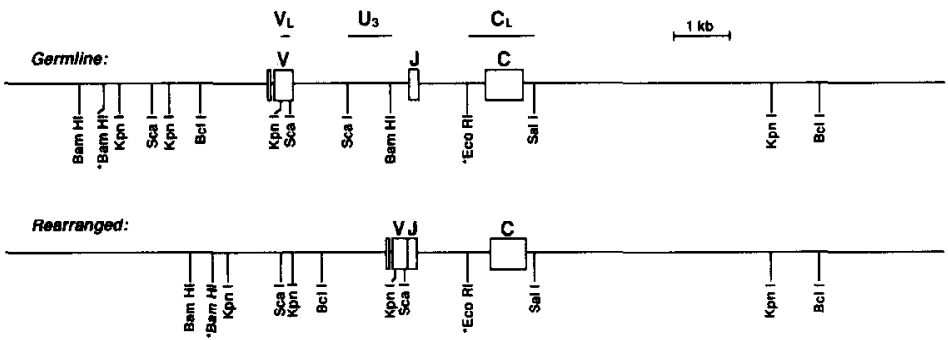

B.

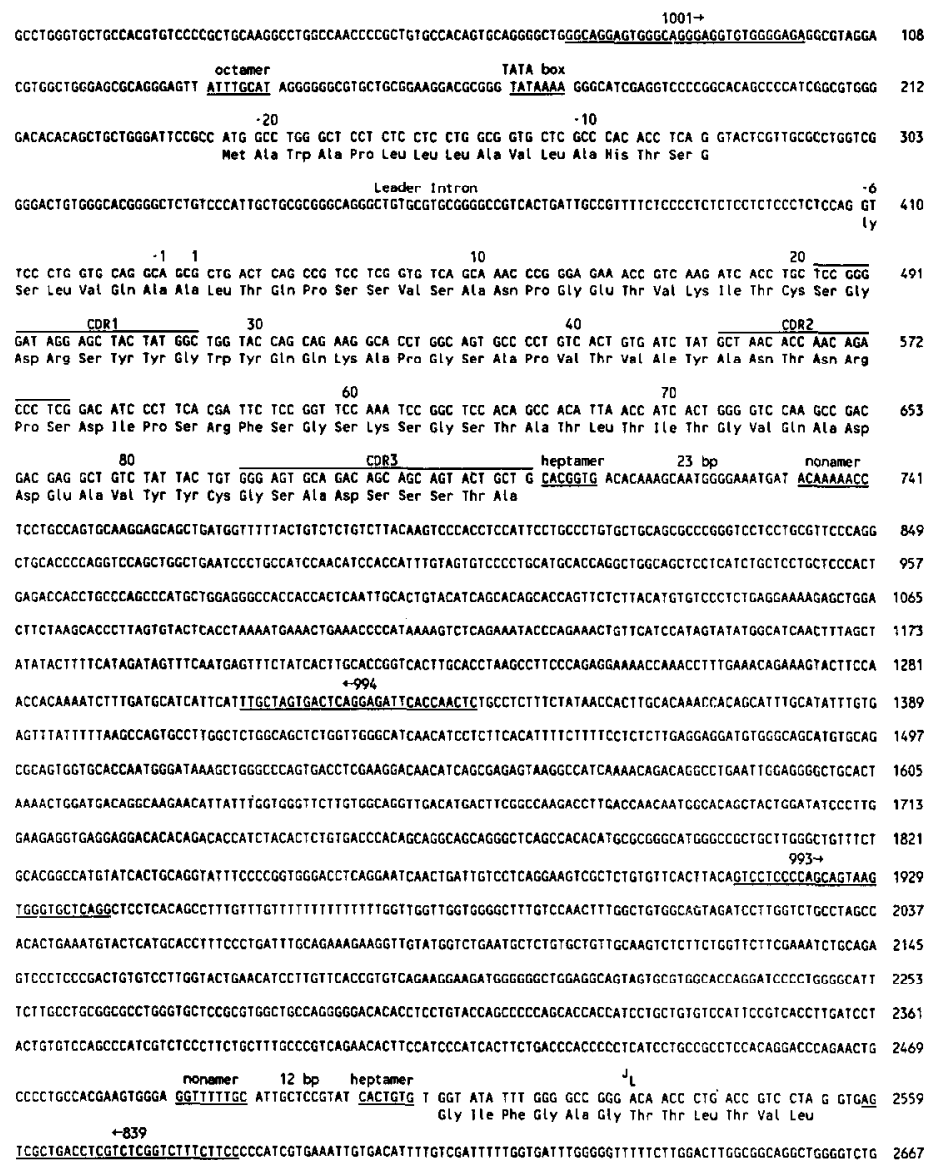

Figure 1. Genomic Organization and Rearrangement of the Chicken $\lg _{\mathrm{L}}$ Locus

(A) Restriction map of the germ-line and rearranged $\lg _{\mathrm{L}}$ locus of the $\mathrm{SC}$ chicken. The DNA sequence is shown as lines (flanking sequence and introns) and open boxes (exons). The two alleles of these $F_{1}$ birds differ at the BamHI and EcoRI sites marked by an asterisk. EcoRI and BamHI polymorphisms remain linked during the rearrangement process. The locations of hybridization probes are indicated by bars above the map.

(B) The nucleotide sequence of the germ-line $V_{L}$ and $J_{L}$ coding segments and the regions in between them was determined from cloned fragments isolated from a White Leghorn chicken genomic library. Underlined sequences include the promoter region octamer and TATA box, the signal sequence heptamers and nonamers, and the PCR primers. The $5^{\prime} \rightarrow 3^{\prime}$ orientations of the PCR primers are indicated by arrows. Complementary determining regions (CDR) are overlined.

\section{Precise Joining of $V_{L}$ and $J_{L}$ Signal Sequences Creates a Circular Episome}

Deletion of the DNA between $V_{L}$ and $J_{L}$ in a clonal $B$ cell line could have occurred by either unequal sister chromatid exchange or intrachromosomal deletion. Okazaki et al. (1987) have shown that at least some TCR $\beta$ gene rearrangements occur by a process of intrachromosomal deletion in which circular DNA molecules are created by ligation of the $V_{\beta}-D_{\beta}$ or $D_{\beta}-J_{\beta}$ signal sequences. To test whether a similar deletional process occurs during chicken Ig gene rearrangement, we designed oligonucleotide PCR primers (\#993 and \#994, Figure 1B) to amplify potential signal joints from embryonic bursal cell DNA. The experimental strategy is diagrammed in Figure 2A. The PCR primers are in opposite orientations in the unrearranged germ-line locus such that no DNA amplification is possible. If the formation of a signal joint creates a circular episomal product, the PCR primers will amplify a fragment approximately $1.2 \mathrm{~kb}$ in size. Should this occur, further characterization of the ligation event is then possible, because perfect heptamer-to-heptamer joining without base loss or addition would result in the creation of a novel ApaLI restriction site (GTGCAC, Figure 2A).

Southern blot analysis of undigested $P C R$ products amplified from day 15 and day 18 bursal cell DNA and hybridized with the $\mathrm{U}_{3}$ probe revealed the expected $1.2 \mathrm{~kb}$ fragment (Figure 4B). Digestion of the PCR products with ApaLI resulted in a complete shift of the $1.2 \mathrm{~kb}$ fragment to the predicted $\sim 600$ bp size (Figure $4 B$ ), suggesting that virtually all signal joints result in the formation of the ApaLI site by precise heptamer-to-heptamer joining. As confirmation of the identity of the amplified segment, digestion with the enzyme BamHI produced the expected $\sim 300$ bp fragment. Signal joints were also cloned, and nucleotide 
A
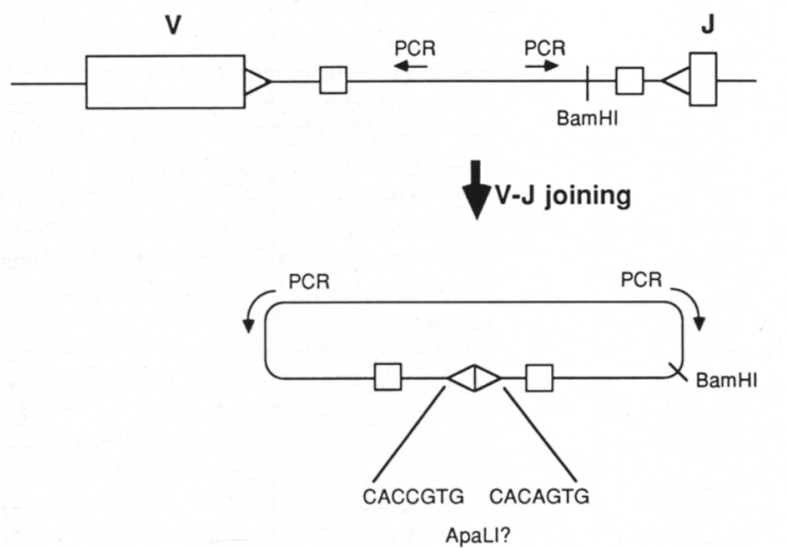

ApaLI?

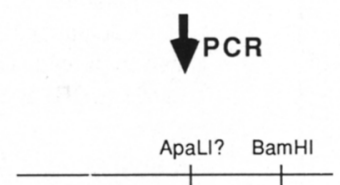

B
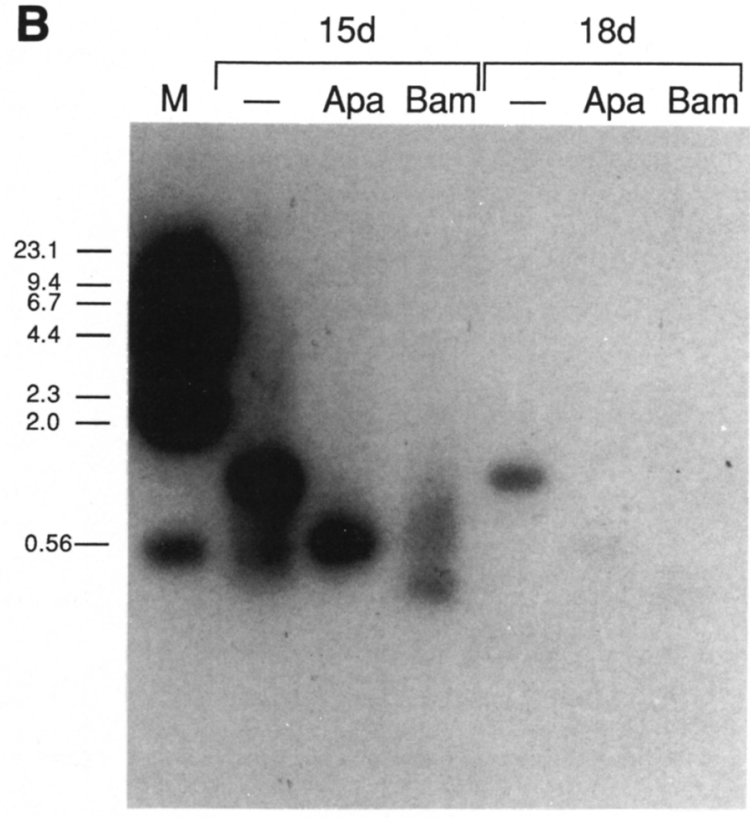

Figure 2. A Signal Joint Episome Is Detectable during Embryonic Development

(A) Schematic representation of the experimental strategy used to recover the signal joint from embryonic bursal lymphocyte DNA by PCR amplification. The signal sequence heptamers and nonamers are represented by triangles and squares, respectively. The position and orientation of PCR primers are indicated by arrows. The location of a known BamHI restriction site and the ApaLl site that may be formed by heptamer-to-heptamer joining are indicated.

(B) The signal joint was amplified from day 15 and day 18 embryonic bursa DNA by PCR with the primers $"$ "993 and \#994. PCR products were untreated (-), or digested with ApaLI or BamHI, prior to separation on a $1 \%$ agarose gel. Southern blots of these samples were hybridized with the $\mathrm{U}_{3}$ probe, and the resulting autoradiogram is shown. Marker bands $(M)$ are the end-labeled fragments of phage $\lambda$ DNA digested with Hindlll, with sizes in $\mathrm{kb}$ indicated.

sequences of the joints were determined. All of the signal joints sequenced had undergone the expected precise joining of heptamer-to-heptamer.

Interestingly, the relative amount of product amplified from day 18 embryonic bursa was less than that from day 15 bursa DNA. This result, which was consistently observed after amplifications of several different DNA preparations from each developmental stage, suggests that the relative abundance of the signal joint episome is lower in the day 18 than in the day 15 bursal DNA sample, and implies that a significant proportion of the bursal lymphocyte population have failed to propagate the episome during this period of development.

\section{Junctional Diversity of Chicken Coding Joints}

In view of the precision with which the signal joint is created and the high percentage of previously sequenced rearranged $\lg _{L}$ genes that are in-frame (Reynaud et al., 1987; Parvari et al., 1987), we next sought to determine the degree of junctional diversity within $\mathrm{V}-\mathrm{J}$ coding joints during early embryonic life. $V-J$ coding joints were isolated from a day 18 embryonic bursal cDNA library and cloned from day 10-18 embryonic bursal and spleen DNA following PCR amplification with primers \#1001 and \#839, located $5^{\prime}$ of $V_{L}$ and $3^{\prime}$ of $J_{L}$, respectively (Figure $1 B$ ). The nucleotide sequences of the $\mathrm{V}-\mathrm{J}$ coding joints are shown in Figure 3. Additional clones from day 18 bursae revealed gene conversion events, which will be reported separately.

We observed extreme junctional diversity at chicken $V-J$ coding joints, with a total of at least 25 different junction sequences represented (Figure 3). Neither the position of recombination within the coding triplets nor the number of codons of $V_{L}$ and $J_{L}$ retained in the rearranged gene is conserved in the $\mathrm{V}-\mathrm{J}$ joints. It is important to note that the exact junction of many clones cannot be determined because the sequence TG is repeated at the $3^{\prime}$ end of $V_{L}$ and at the $5^{\prime}$ end of $J_{L}$. However, at least 6 sites within $V_{L}$ and 11 sites within $J_{L}$ were used in $V-J$ joining events. The maximal extent of base loss before joining was 11 nucleotides from $V_{L}$ (clone 17) and 14 nucleotides from $J_{\mathrm{L}}$ (clone 37).

Whereas all previously reported embryonic chicken $\mathrm{V}-\mathrm{J}$ joints are in-frame, nonproductive joints were found in the $\mathrm{V}-\mathrm{J}$ joints amplified from embryonic tissue by PCR (Figure 3). The percentage of clones with out-of-frame joints found between days 10-12 of embryogenesis was $66 \%$, further suggesting that $V-J$ joining is a random process. The lower frequency of out-of-frame joints observed at later stages of embryonic development suggests that the 


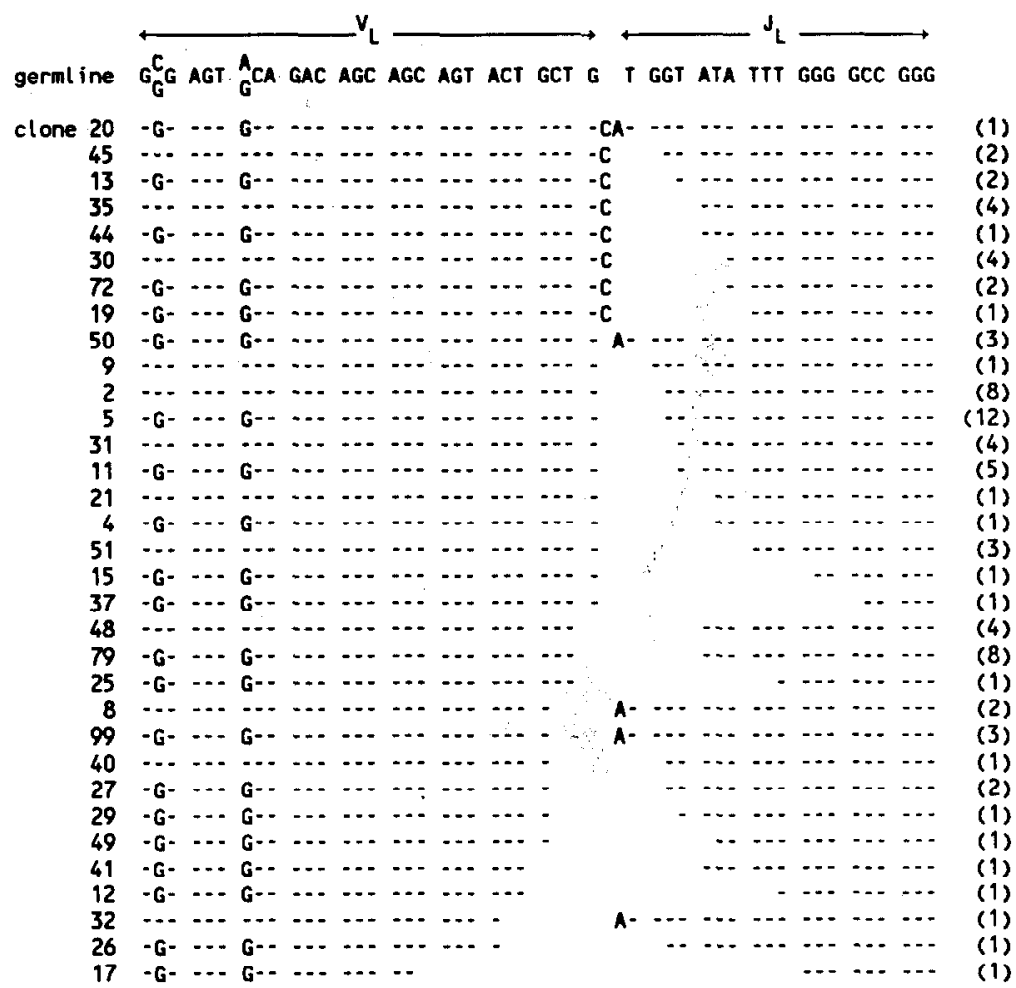

Figure 3. Nucleotide Sequences of $\mathrm{V}-\mathrm{J}$ Joints Germ-line $V_{L}$ and $J_{L}$ sequences of each allele of the heterozygous SC strain were determined after PCR amplification of the $\mathrm{lg}_{\mathrm{L}}$ locus from erythrocyte DNA of each parental strain. Sequence polymorphisms in codons $84(\mathrm{C} / \mathrm{G})$ and 86 (A/G) between the parental strains of our $F_{1}$ birds allowed us to confirm that rearrangements of both alleles were isolated with approximately equal frequency. The nucleotide sequences of the $V-J$ joints $\left(V_{L}\right.$ codons 84-92 through $J_{\mathcal{L}}$ of rearranged genes are compared with the germ-line sequences obtained from the SC chicken. Identity to the top germ-line sequence is indicated by a dash. All joint sequences were cloned from spleen and bursa tissue from days 10-18 of embryonic development. The total number of clones with each junction sequence shown is given in parentheses. bursa is a site for the selective amplification of cells with productive $V-J$ joints (McCormack et al., submitted).

\section{Nonrandom Nucleotides at $\mathbf{V}-\mathbf{J}$ Junctions}

Ten clones (four isolated by CDNA cloning and six isolated by PCR amplification) encoded $V-J$ joints with an $A$ nucleotide at the junction that is not found in the germ-line $V_{L}$ or $J_{L}$ segments. In each case, the $V-J$ junction may be written such that the A nucleotide occurs at the $5^{\prime}$ end of a full-length $J_{L}$ gene segment. In addition, 17 clones were found that encoded $V-J$ joint sequences with an additional $\mathrm{C}$ nucleotide, which appears to be added in each case to the $3^{\prime}$ end of a full-length $V_{L}$ gene segment. Of note, one sequence (clone 20) encodes full-length $V_{L}$ and $J_{L}$ segments, and contains both added nucleotides $(C$ and $A$ ) at the junction. In order to characterize the positional nature and frequency with which we observe nucleotide addition during $\mathrm{V}-\mathrm{J}$ joining further, the positions of $V_{L}$ and $J_{L}$ recombination among the 85 clones were tabulated (Figure 4). The frequency with which a

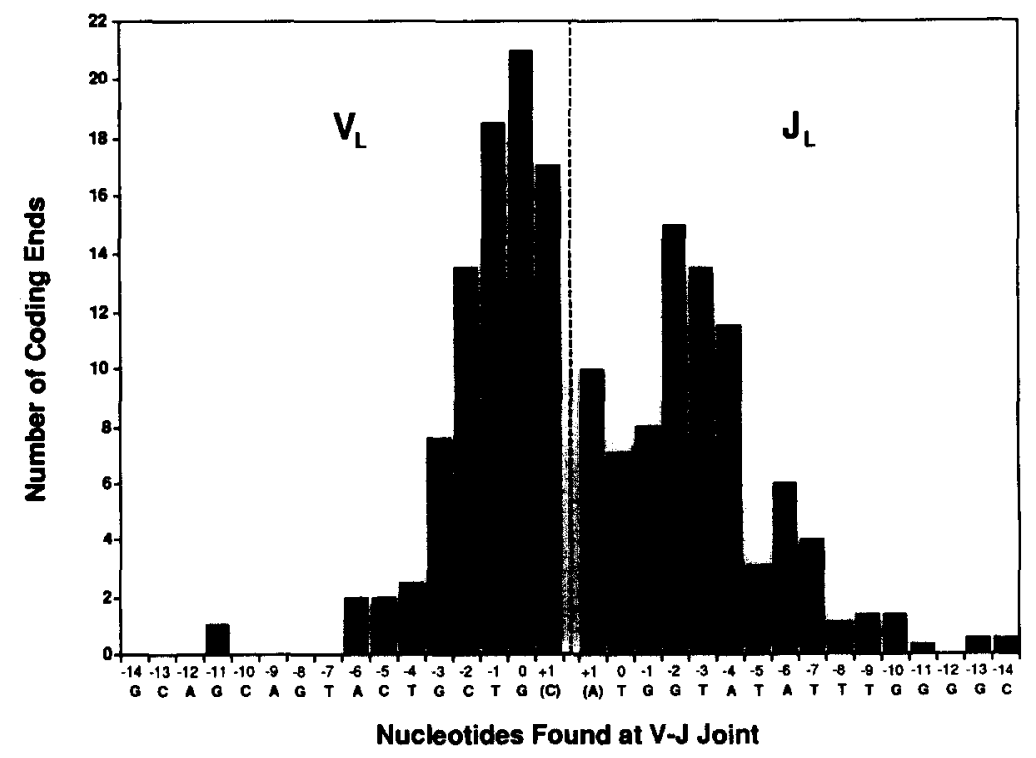

Figure 4. $V_{L}$ and $J_{L}$ Nucleotides Flanking the $V-J$ Joint

The coding joints shown in Figure 3 were used to create a histogram depicting the number of times individual base pairs occurred at the $\mathrm{V}-J$ joint. For a $\mathrm{V}-\mathrm{J}$ joint that may be derived from alternate joining events, each alternative is counted as $1 / n$, where $n$ is the number of alternative events. The germ-line $V_{L}$ and $J_{L} s e-$ quences are indicated, with the added $C$ and A nucleotides in parentheses. 
given base pair occurs at the $V-J$ junction appears to be dependent on its distance from the end of the $V_{L}$ or $J_{L}$ coding sequence. The frequency with which we observe the additional $C$ or $A$ nucleotides, which we have assigned the +1 positions of $V_{L}$ and $J_{L}$, respectively, is comparable to the frequency with which neighboring nucleotides are utilized. Possible origins of the $C$ and $A$ nucleotides are discussed below.

\section{Discussion}

The studies described in this paper characterize the molecular events associated with $\mathrm{V}-\mathrm{J}$ joining at the chicken $\lg _{\mathrm{L}}$ locus. Consistent with previous reports (Reynaud et al., 1985; Thompson and Neiman, 1987), $\lg _{\mathrm{L}}$ gene rearrangement results in the removal of the $1.8 \mathrm{~kb}$ of germ-line DNA between $V_{L}$ and $J_{L}$. The rearrangement occurs as a result of an intrachromosomal deletion that removes a circular episomal element in which the conserved heptamers $3^{\prime}$ of $V_{L}$ and $5^{\prime}$ of $J_{L}$ are precisely joined. No evidence for nucleotide addition or deletion at the signal joint was obtained. Previous examples of nucleotide addition or deletion at signal joints have occurred in cells in which Ig or TCR gene rearrangement is an ongoing event (Lieber et al., 1988b; Okazaki et al., 1987). In these cases nucleotide addition or deletion may have been derived from imprecise excision near the heptamer borders, or may be the result of secondary rearrangements involving the signal joint. During secondary rearrangements, one half of the signal joint would be treated by the recombinase as a "coding" end, and therefore would be susceptible to nudleotide loss or addition.

Despite the precision observed in the generation of the signal joint, joining of the chicken $V_{L}$ and $J_{L}$ coding segments appears to occur randomly. Just as in mammals, the coding ends appear susceptible to exonucleolytic activity prior to their ligation to form a coding joint. While the random nature of $\mathrm{V}-\mathrm{J}$ joining leads to a considerable proportion of rearrangements being out-of-frame, it also serves to generate diversity within the $\mathrm{V}-\mathrm{J}$ joining region of in-frame clones. The chicken $V-J$ coding joint sequences also revealed the presence of unexpected $C$ and/or $A$ nucleotides at the junctions. Based on the data presented in Figure 4, it seems possible that every $V_{L}$ segment has a $3^{\prime} \mathrm{C}$ added and every $\mathrm{J}_{L}$ segment a $5^{\prime} A$ added during the rearrangement process. Alternatively, the $\mathrm{C}$ or $\mathrm{CA}$ nucleotides may originate from the dinucleotide CA immediately $3^{\prime}$ of the germ-line $V_{L}$ gene segment in the signal sequence heptamer. In these cases, cleavage may occur $3^{\prime}$ of the $\mathrm{C}$ or $\mathrm{A}$ nucleotide of the heptamer. However, the uniform presence of the ApaLI restriction site in the signal joints we have isolated (Figure 2B) suggests that the $C$ or $C A$ is not lost from the heptamer during $\mathrm{V}-\mathrm{J}$ joining; therefore cleavage $3^{\prime}$ of $\mathrm{C}$ or $\mathrm{CA}$ would have to result in a staggered cut that is repaired during ligation. There does not appear to be a simple way of generating the A nucleotide alone from the germ-line signal sequences.

Six of the clones that contain either the $C$ or the $A$ nucleotide were isolated from the bursa at day 18 of em- bryonic development. A possible somatic origin of the added nucleotides in these clones is gene conversion, which has been initiated by this time of embryonic development (Reynaud et al., 1987; Thompson and Neiman, 1987). However, most of the clones with the junctional $C$ and/or $A$ were isolated from day 10-15 embryonic tissue, a time period during which we have failed to observe other examples of $\mathrm{Ig}_{\mathrm{L}}$ gene conversion (McCormack et al., submitted). In addition, 7 of 26 clones (26.9\%) containing the extra $\mathrm{C}$ and/or $\mathrm{A}$ nucleotide were isolated from embryonic $B$ cells in the spleen at a developmental stage prior to bursal selection and gene conversion. The percentage of splenic clones with $C$ and/or $A$ was comparable to the total number of clones isolated from splenic tissue (23/85 = $27.1 \%$ ). These data further argue against roles for bursal selection or gene conversion in the addition of $C$ or $A$ nucleotide.

In mammals, additional non-germ-line base pairs have been observed frequently in rearranged Ig heavy chain genes. This nucleotide addition is thought to be due to the action of terminal deoxynucleotidyl transferase (TdT), and usually results in the addition of G-rich sequences termed "N segments" (Alt and Baltimore, 1982; Alt et al., 1986). Whereas $\mathrm{N}$ segments are generally associated only with $\mathrm{lg}_{\mathrm{H}}$ gene rearrangement (Yancopoulos and Alt, 1986), at least two examples of $\lg _{\kappa}$ gene rearrangement with base insertion have been reported (Max et al., 1980; Klobeck et al., 1987), and $\mathbf{N}$ segments are added to coding joints of recombination constructs in vitro (Lieber et al., 1988a). The nucleotides added to the chicken $V-J$ joints do not resemble random $N$ segments for two reasons. First, the extra nucleotides are always $\mathrm{C}$ and/or $\mathrm{A}$ rather than a G-rich polynucleotide region. Second, the added nucleotides are restricted in position, i.e., an extra $\mathrm{C}$ nucleotide appears only at $V-J$ junctions in which there has been no apparent base loss from the $V_{L}$ gene segment, and an extra A nucleotide appears only when there has been no base loss from the $J_{L}$ gene segment.

Some reports of $\mathrm{N}$ segment addition suggest that specific codons may be added at junctions by a complex sequence-specific and/or template-free mechanism. For example, the serine residue at position 99 of anti-arsonate $\mathrm{H}$ chains, which is selected at the protein level for binding to the hapten arsonate, is encoded by an $\mathrm{N}$ segment (Milner et al., 1986; Wysocki et al., 1986). It could be argued that some instances of $A$ addition at in-frame chicken $V-J$ junctions produce a specific codon (e.g., the aspartic acid codon GAT in clones 50, 8 , and 99) which could be selected at the amino acid level. However, this selection would have to occur prior to exposure to exogenous antigen or bursal selection, because two of these sequences were identified in clones isolated from splenic tissue at day 12 of embryonic development. Additional A nucleotides were also observed in an out-of-frame joint and in a joint codon encoding asparagine.

Our findings concerning the rearrangement of the chicken $\mathrm{lg}_{\mathrm{L}}$ genes have led us to consider various models to account for the observed features of Ig gene rearrangement. Any model of molecular recombination must account for the observation that during rearrangement the 
$V$ and $J$ coding ends appear to be susceptible to exonucleases and/or TdT, whereas the signal ends are protected from these activities. To account for these observations, it has been suggested that the DNA recombination events involved in $V-J$ joining occur sequentially, with the signal joints being made first and the coding ends being joined later (Alt and Baltimore, 1982). During the time between creation of the signal joint and the coding joint, the coding ends would be susceptible to base loss or addition. However, a sequential model no longer seems likely because it has recently been observed in a mammalian in vitro recombination system that coding ends can be separated from and then rejoined to signal ends ("open-and-shut" joints, S. Lewis, personal communication). During these events the coding ends still display sensitivity to base pair addition and loss, while the signal ends are protected from these processes. These data suggest that all four DNA ends are available for ligation at the same time, rather than ligated sequentially (Lieber et al., 1988a).

The above data and the data presented in this paper could be accounted for by a novel mechanism of gene rearrangement. In this model, we propose that the "recombinase" complex exchanges a $\mathrm{C}$ nucleotide for the signal sequence $3^{\prime}$ of the $V_{L}$ segment. The result of this process would be that the signal sequence would become bound to the "recombinase" complex and the $V_{L}$ coding sequence would now end in a $3^{\prime}$ non-germ-line $C$. A similar exchange would occur between the "recombinase" complex and the $5^{\prime}$ end of the $J_{L}$ segment. In this case the signal sequence would be exchanged for an A nucleotide. The generation of these molecular intermediates would leave the coding sequences susceptible to base addition and/or deletion while protecting the signal sequences from these processes. The entire exchange process may occur on a single strand. The second strand could then be resolved by either DNA replication or template-directed repair. This model may help to explain why mice, which are deficient in ligation activity associated with Ig "recombinase," can still form some signal joints but not $\mathrm{V}-\mathrm{J}$ coding joints (Lieber et al., 1988b). If the signal sequences are incorporated into and protected by the "recombinase" complex, they may be more likely to be resolved over time by whatever residual ligase activity the cells retain or joined by homologous recombination. The validity of this alternative model of Ig gene rearrangement should be testable in the future in a variety of experimental systems.

\section{Experimental Procedures}

\section{Chicken Strains}

Chickens used in these experiments were Hyline SC birds, an $F_{1}$ cross between two inbred $B^{2}$ chicken strains that differ in several restriction enzyme sites around the $\lg _{\mathrm{L}}$ locus (Thompson and Neiman, 1987). Blood samples from the parental strains were obtained from $\mathrm{Hy}$ line Incorporated.

DNA Preparation and Hybridizations

DNA preparation and hybridization methods have been described (Thompson and Neiman, 1987). Hybridization probes are illustrated in Figure 1A. A 964 bp Scal-BamHIl genomic fragment $\left(U_{3}\right)$ between $V_{L}$ and $J_{L}$ was used as a hybridization probe to identify the signal joint product. Rearranged $V_{L}$ gene cDNA clones were identified by hybridization with a $V_{L}$ probe (180 bp Kpnl-Scal fragment) and a $C_{L}$ probe (1.2 kb EcoRl-Sall fragment).

\section{DNA LIbraries}

A Hyline SC chicken bursa cDNA library was prepared from day $18 \mathrm{em}$ bryonic bursa mRNA and cloned into the vector $\lambda 345$ (T. St. John, personal communication). Selected cDNA clones were recovered from the phage vector as plasmids by digestion with Sfil and self-ligation. A chicken genomic DNA library, prepared by partial Sau3A digestion of erythrocyte DNA from an outbred White Leghorn chicken and cloned into $\lambda$-FIX (Stratagene), was kindly provided by K. Conklin (University of Minnesota). Genomic fragments were subcloned into the plasmid vector pGEM-3Z (Promega).

\section{Polymerase Chain Reaction (PCR)}

PCR (Saiki et al., 1988) was used to rapidly clone the reciprocal signal joint created during $V_{-} J$ joining; multiple joining events that occurred between the chicken $V_{L}$ and $J_{L}$ gene segments; and the two germ-line $\mathrm{Ig}_{\mathrm{L}}$ alleles from the SC chicken. The oligonucleotide primers (Figure 1B) were designed with restriction sites (EcoRI or HindlII) at their $5^{\prime}$ ends to allow directional cloning into PGEM-3Z, and were synthesized on an Applied Biosystems Model 380B DNA synthesizer.

Typical PCR reactions consisted of 0.2-1 $\mu \mathrm{g}$ of DNA template, $1 \mu \mathrm{g}$ of each primer, $0.1 \mathrm{mM}$ of each dNTP, $10 \mathrm{mM}$ Tris-HCl (pH 8.3), $50 \mathrm{mM}$ $\mathrm{KCl}, 1.5 \mathrm{mM} \mathrm{MgCl}_{2}, 0.01 \%$ gelatin, and $2 \mathrm{mM}$ dithiothreitol. PCR reactions were performed with $2.5 \mathrm{U}$ of Taq polymerase (Celus) in a PerkinElmer thermal cycler for 30 cycles, followed by a final 10 min extension reaction. Each cycle for the amplification of germ-line and rearranged Ig genes consisted of $94^{\circ} \mathrm{C}$ for $1.25 \mathrm{~min}$ and $72^{\circ} \mathrm{C}$ for $3-5 \mathrm{~min}$. Amplification of signal joints was performed with the addition of a $55^{\circ} \mathrm{C}$ annealing step for $1 \mathrm{~min}$. Following digestion of PCR products with EcoPI and HindIII and cloning into PGEM-3Z, colonies positive for hybridization with the $V_{L}$ probe were randomly selected for sequencing. Individual colonies were used for the analysis of $V-J$ coding and signal joints. To randomize Taq polymerase errors and allow reading of a consensus sequence for the two germ-line $\lg _{\mathrm{L}}$ alleles, colonies were pooled for plasmid DNA preparation.

\section{DNA Sequencing}

Dideoxynucleotide sequencing reactions were performed using doublestranded plasmid template DNA with a Sequenase kit according to the supplier's protocols (U. S. Biochemical Corp.), and separated on $50 \mathrm{~cm}$ wedge gels $(0.2-0.6 \mathrm{~mm})$ using a buffer gradient. All sequences were confirmed by sequencing both strands, using oligonucleotide primers specific for the SP6 and T7 promoter sites of pGEM-3Z, and 17- to 20-

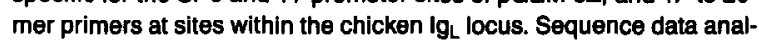
ysis was performed using the DNASTAR software package.

\section{Acknowledgments}

We would like to thank Kathy Conklin for providing the chicken genomic library, and Sheila Norton for oligonucleotide syntheses. The cDNA library was produced in the laboratory of Paul Neiman, with the assistance of Tom St. John. We would like to thank Paul Neiman, Ken Roux, Brian Van Ness, Wesley Dunnick, J. Latham Claflin, Jeff Bonadio, John Lowe, and Jeff Leiden for thoughtful review of the manuscript and helpful discusssions. We thank Susanna Lewis for sharing data with us prior to publication. We also thank Jeanelle Pickett for assistance in preparing the manuscript and Beverly Burck for the preparation of figures. This work was supported in part by Public Health Service Award CA41450 from the National Cancer Institute to E. H. H.

The costs of publication of this article were defrayed in part by the payment of page charges. This article must therefore be hereby marked "advertisement" in accordance with 18 U.S.C. Section 1734 solely to indicate this fact.

Received November 22, 1988; revised December 21, 1988.

\section{References}

Akira, S., Okazaki, K., and Sakano, H. (1987). Two pairs of recombina- 
tion signals are sufficient to cause immunoglobulin $V-(D)-J$ joining. Science 238, 1134-1138.

Alt, F. W., and Baltimore, D. (1982). Joining of immunoglobulin heavy chain gene segments: implications from a chromosome with evidence of three $D-J_{H}$ fusions. Proc. Natl. Acad. Sci. USA 79, 4118-4122.

Alt, F. W., Blackwell, T. K., DePinho, R. A., Reth, M. G., and Yancopoulos, G. D. (1986). Regulation of genome rearrangement events during lymphocyte differentiation. Immunol. Rev. 89, 5-30.

Hood, L., Kronenberg, M., and Hunkapiller, T. (1985). T cell antigen receptors and the immunoglobulin supergene family. Cell 40, 225-229. Klobeck, H.-G., Combriato, G., and Zachau, H. G. (1987). N segment insertion and region-directed somatic hypermutation in a kappa gene of a t $(2 ; 8)$ chromosomal translocation. Nucl. Acids Res. 15, 4877-4888. Kronenberg, M., Siu, G., Hood, L. E., and Shastri, N. (1986). The molecular genetics of the T-cell antigen receptor and $\mathrm{T}$-cell recognition. Annu. Rev. Immunol. 4, 529-591.

Lieber, M. R., Hesse, J. E., Mizuuchi, K., and Gellert, M. (1988a). Lymphoid $\mathrm{V}(\mathrm{D}) \mathrm{J}$ recombination: nucleotide inser tion at signal joints as well as coding joints. Proc. Natl. Acad. Sci. USA 85, 8588-8592.

Lieber, M. R., Hesse, J. E., Lewis, S., Bosma, G. C., Rosenberg, N., Mizuuchi, K., Bosma, M. J., and Gellert, M. (1988b). The defect in murine severe combined immune deficiency: joining of signal sequences but not coding segments in $V(D) J$ recombination. Gell $55,7-16$

Max, E. E., Seidman, J. G., Milier, H., and Leder, P. (1980). Variation in the crossover point of kappa immunoglobulin gene $V-J$ recombination: evidence from a cryptic gene. Cell 21, 793-799.

Milner, E. C. B., Meek, K. D., Rathbun, G., Tucker, P., and Capra, J. D. (1986). Are anti-arsonate antibody $\mathrm{N}$-segments selected at both the protein and the DNA level? Immunol. Today $7,36-40$.

Okazaki, K., Davis, D. D., and Sakano, H. (1987). T cell receptor $\beta$ gene sequences in the circular DNA of thymocyte nuclei: direct evidence for intramolecular DNA deletion in V-D-J joining. Cell 49, 477-485.

Parvari, R., Ziv, E., Lentner, F., Tel-Or, S., Burstein, Y., and Schechter I. (1987). Analyses of chicken immunoglobulin light chain cDNA clones indicate a few germline $V \lambda$ genes and allotypes of the $C \lambda$ locus. EMBO J. 6, 97-102.

Reynaud, C.-A., Anquez, V., Dahan, A., and Weill, J.-C. (1985). A single rearrangement event generates most of the chicken immunoglobulin light chain diversity. Cell 40, 283-291.

Reynaud, C.-A., Anquez, V., Grimal, H., and Weill, J.-C. (1987). A hyperconversion mechanism generates the chicken light chain preimmune repertoire. Cell 48, 379-388.

Saiki, R. K., Gelfand, D. H., Stoffel, S., Scharf, S. J., Higuchi, R., Horn G. T., Mullis, K. B., and Erlich, H. A. (1988). Primer-directed enzymatic amplification of DNA with a thermostable DNA polymerase. Science 239, 487-491.

Thompson, C. B., and Neiman, P. E. (1987). Somatic diversification of the chicken immunoglobulin light chain gene is limited to the rearranged variable gene segment. Cell 48, 369-378.

Tonegawa, S. (1983). Somatic generation of antibody diversity. Nature $302,575-581$.

Wysocki, L. J., Manser, T., Gridley, T., and Gefter, M. L. (1986). Molecular limitations on variable-gene junctional diversity. J. Immunol. 137 3699-3701.

Yancopoulos, G. D., and Alt, F. W. (1986). Regulation of the assembly and expression of variable-region genes. Annu. Rev. Immunol. 4 , 339-368.

Yancopoulos, G. D., Blackwell, T. K., Suh, H., Hood, L., and Alt, F. W. (1986). Introduced $T$ cell receptor variable region gene segments in pre-B cells: evidence that $B$ and $T$ cells use a common recombinase. Cell 44, 251-259.

\section{Note Added in Proof}

The data referred to as $\mathrm{S}$. Lewis, personal communication, have been published: Lewis et al., Cell 55, 1099-1107. 